\title{
H. Smoleńska
}

Gdańsk University of Technology, Faculty of Mechanical Engineering, Department of Materials Science and Engineering, Gdansk, Poland

\section{EFFECTS OF THE TIME AND TEMPERATURE ON THE OXIDE SCALE FORMED ON THE COBALT ALLOYS}

\begin{abstract}
The cobalt base PTA (Plasma Transferred Arc) clad layers were investigated under different temperature and time of oxidation. The microstructure of the clads after oxidation demonstrated degradation process which led to the decomposition of the dendrite boundaries. Chemical compositions of the formed scales were depending on the oxidation temperature, chemical composition of the alloy, especially small addition of the silicon, and time of the exposition.
\end{abstract}

Key words: cobalt base alloy, oxidation scale silicon

\section{INTRODUCTION}

The sever service conditions need materials which have high strength and adequate resistance to oxidation at elevated temperatures. A wide range of compositions based on nickel, cobalt and nickel-iron. Their various applications are based largely on their suitability at higher temperatures to a particular environment. During recent decades, the high-temperature oxidation on structural materials, such as $\mathrm{Fe}-\mathrm{Co}$-, and Ni-base alloys, for which high-temperature oxidation resistance is an important parameter, has been investigated intensively. In general, these alloys, developed good oxidation resistance by possessing proper amounts of $\mathrm{Al}, \mathrm{Cr}$, and $\mathrm{Si}$ and are called as alumina, chromia, and silica formers. The classification of the material depends on which oxide is formed after achieving steady-state conditions. For chromia formers, maximum protection against oxidation is obtained only if a continuous and coherent $\mathrm{Cr}_{2} \mathrm{O}_{3}$ scale layer is formed and maintained. That alloys must have a sufficient chromium content to initially form a chromium oxide and supply of chromium by diffusion within the underlying alloy in order to continuous growth of the protective scale. [1]. In spite of the long history of the investigation of oxidation and oxide scales, there are still many aspects of this phenomenon that are not well understood. Our incomplete understanding of scale formation and evolution is due both to the extraordinary complexity of the process and to the limited availability of tools that allow a complete characterization of the scales themselves [2]. The growing of the protective oxide scale must caused different processes which involved selective oxidation of alloy elements and lead to changing of the alloy composition in the subsurface region and even phase 
transformation may occur. Typically it is scale formation and subsurface degradation. As the time passed the scale may change its chemical composition. The degradation of the alloy may be for example phase formation or dissolution and formation of voids [3].

\section{EXPERIMENTAL}

The clad layers were made from the powder, by PTA technology, on the A-R-H10S2M (X40CrSiMo10-2) steel base by CASTOLIN equipment EUTRONIC GAP 200. The layer consisted of three sublayers with three tracks for each one. The subsequent tracks were overlapped by $30-40 \%$. Chemical composition of the powder which was used for

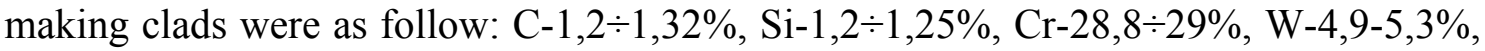
$\mathrm{Ni}-2,2 \%$, Mo- $<0,1 \%$, Fe- 1,9 $\div 2,0 \%$, and $\mathrm{Co}$ as balance. The oxidation studies were performed in ambient air by two modes: isothermal at $850^{\circ} \mathrm{C}$ and $950^{\circ} \mathrm{C}$ for 200 hours and by two cycles , 200 hours each (total time 400 hours) at $750^{\circ} \mathrm{C}$ (the first cycle) and $900^{\circ} \mathrm{C}$ (the second cycle) using laboratory electric tube furnace. The analytical techniques used to characterize the samples included optical microscopy, scanning electron microscopy (SEM), energy dispersive spectroscopy (EDS) and X-ray powder diffraction (XRD). SEM was conducted at accelerating voltages ranging from $15-30 \mathrm{kV}$ in backscattered and secondary electron imaging modes.

\section{RESULTS AND DISCUSSION}

Oxidation in air of the cobalt base alloys led to weight gain due to the formation of chromia + spinel scales and surface-connected grain boundary pits or oxides $[4 \div 8]$. For all the cases the scale layers on the surface of the clad on the cross-section were noticed but differences were obvious. For oxidation at $850^{\circ} \mathrm{C}, 200$ hours, the scale was dense, an approximately $6 \mu \mathrm{m}$ thick (Fig. 1). The negligible traces of internal oxidation were noticed. After oxidation at higher temperature, $950^{\circ} \mathrm{C}-$ the scale was thicker and the outer part of the scale showed tendency to cracking and spalling. The internal oxidation on the dendrites boundaries was also observed. The degradation of clad material reached about $34 \mu \mathrm{m}$ (Fig.2). For both cases chemical compositions of the scales were very similar and the XRD analysis reviled generally $\mathrm{Cr}_{2} \mathrm{O}_{3}$ presence in the scales. For two cycle oxidation and 400 hours - the inner part of the scale was dense, similar to this from Fig. 1, but the outer part was cracked and partially spalled. The total scale thickness was about $11 \mu \mathrm{m}$. In this case chemical composition of the scale was different. Beside chromium the presence of small amounts of cobalt and silicon were found. The trends of this chemical changes are presented on the Fig. 4. Primary oxide product at the early stage of oxidation was $\mathrm{Cr}_{2} \mathrm{O}_{3}$. The 400 hours time of oxidation was long enough for diffusion processes which resulted with the change of the scale composition and probably little amount of $\mathrm{CoO}$ or $\mathrm{CoCr}_{2} \mathrm{O}_{4}$ spinel structure was formed. This scale composition was typical for cobalt chromium alloys which were at least contaminated with silicon and if 0,05 weight percent silicon was added to the $\mathrm{Co}-25 \mathrm{Cr}$ - 
1.0C alloy, then parabolic oxidation rates two orders of magnitude lower were recorded $[9,10]$.

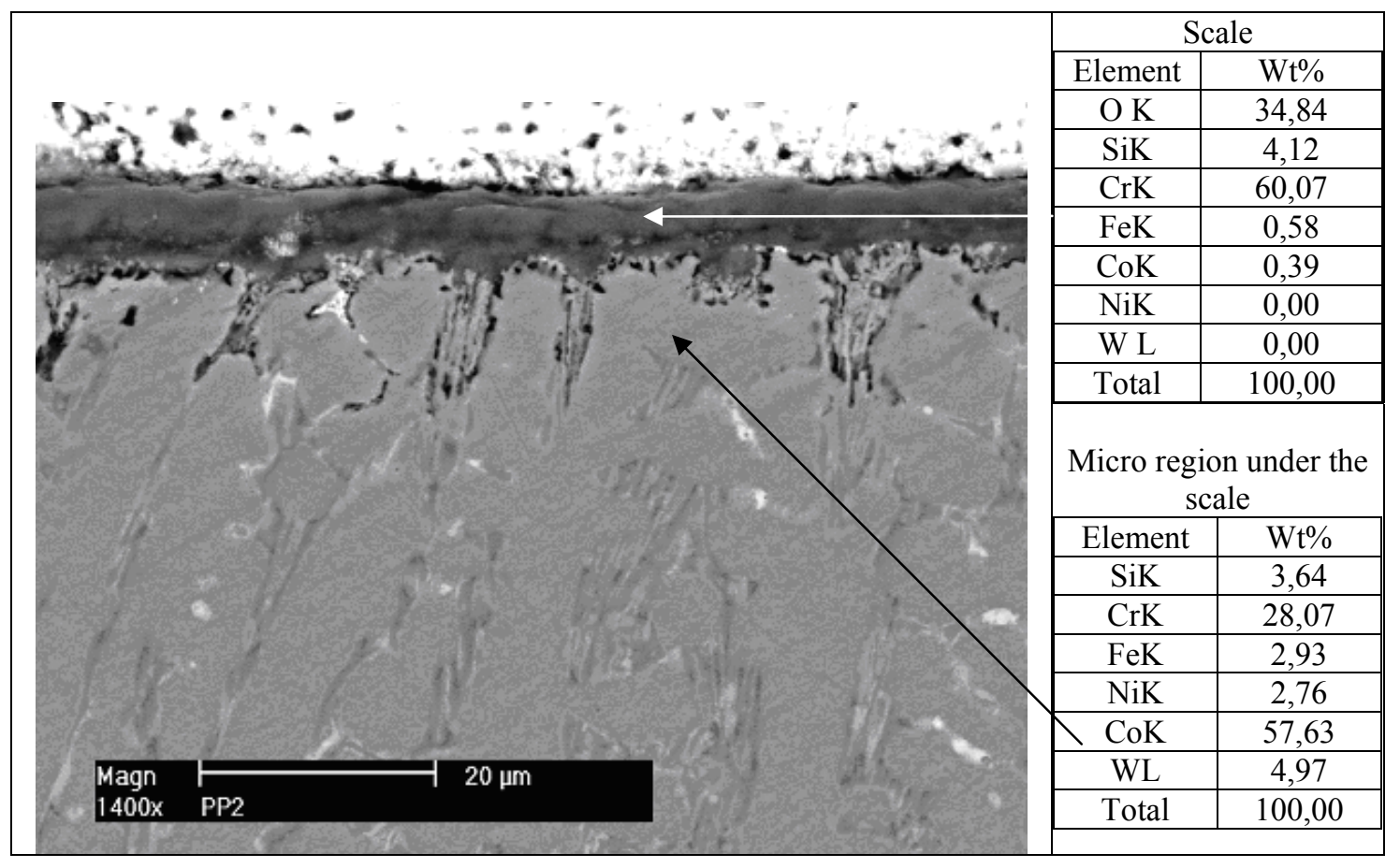

Fig. 1. Cross-section of the clad layer, close to the surface, oxidation at $850^{\circ} \mathrm{C}$ for 200 hours and chemical composition of the scale (EDS point analysis) and microregion under the scale

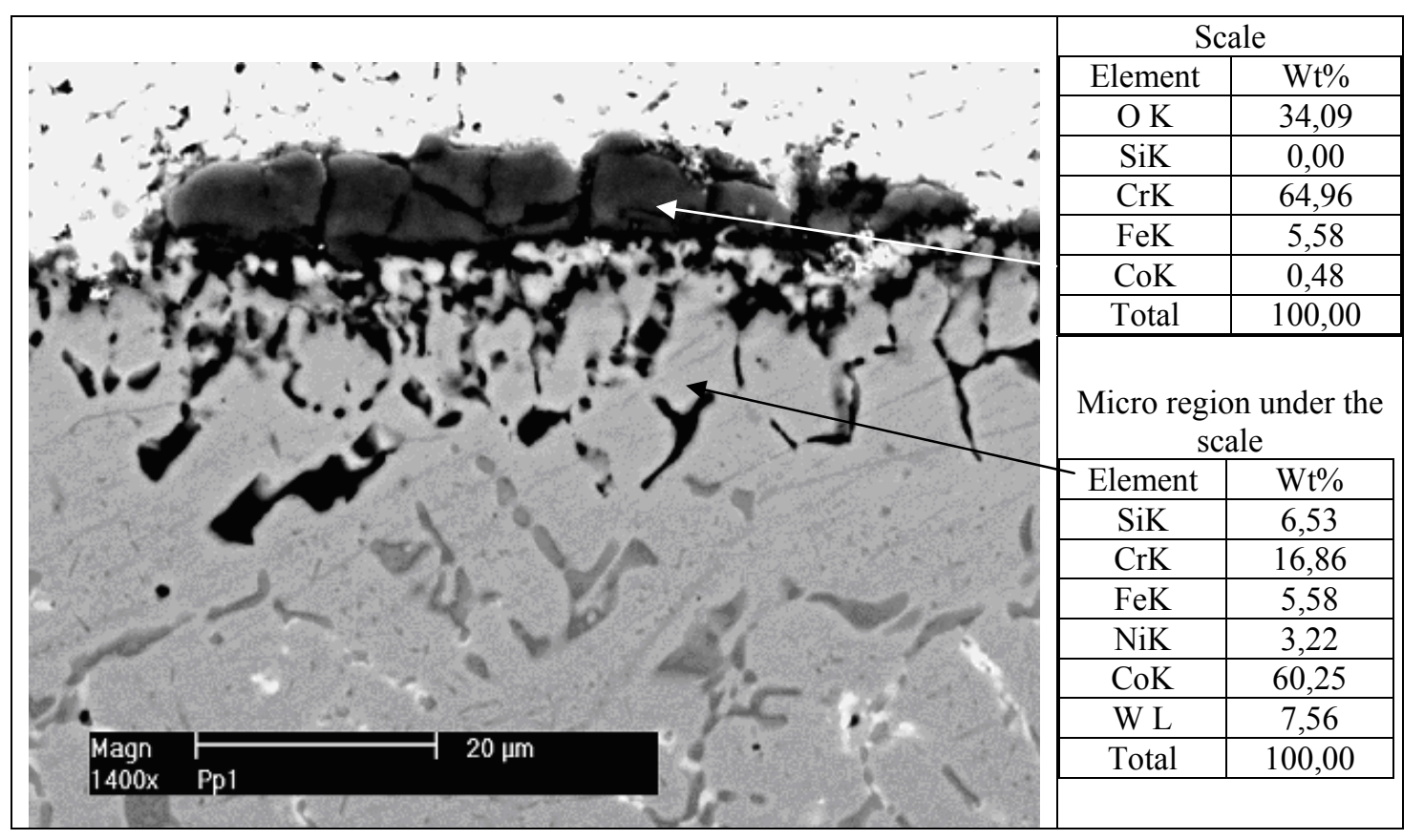

Fig. 2. Cross-section of the clad layer, close to the surface, oxidation at $950^{\circ} \mathrm{C}$ for 200 hours and chemical composition of the scale (EDS point analysis) and microregion under the scale

It was concluded that silicon has its effect at the alloy surface by promoting $\mathrm{Cr}_{2} \mathrm{O}_{3}$ formation $[11,12]$. This behavior of silicon was also indicated by chemical composition of the region just under the scale (Fig.5) and increase of its amount. 


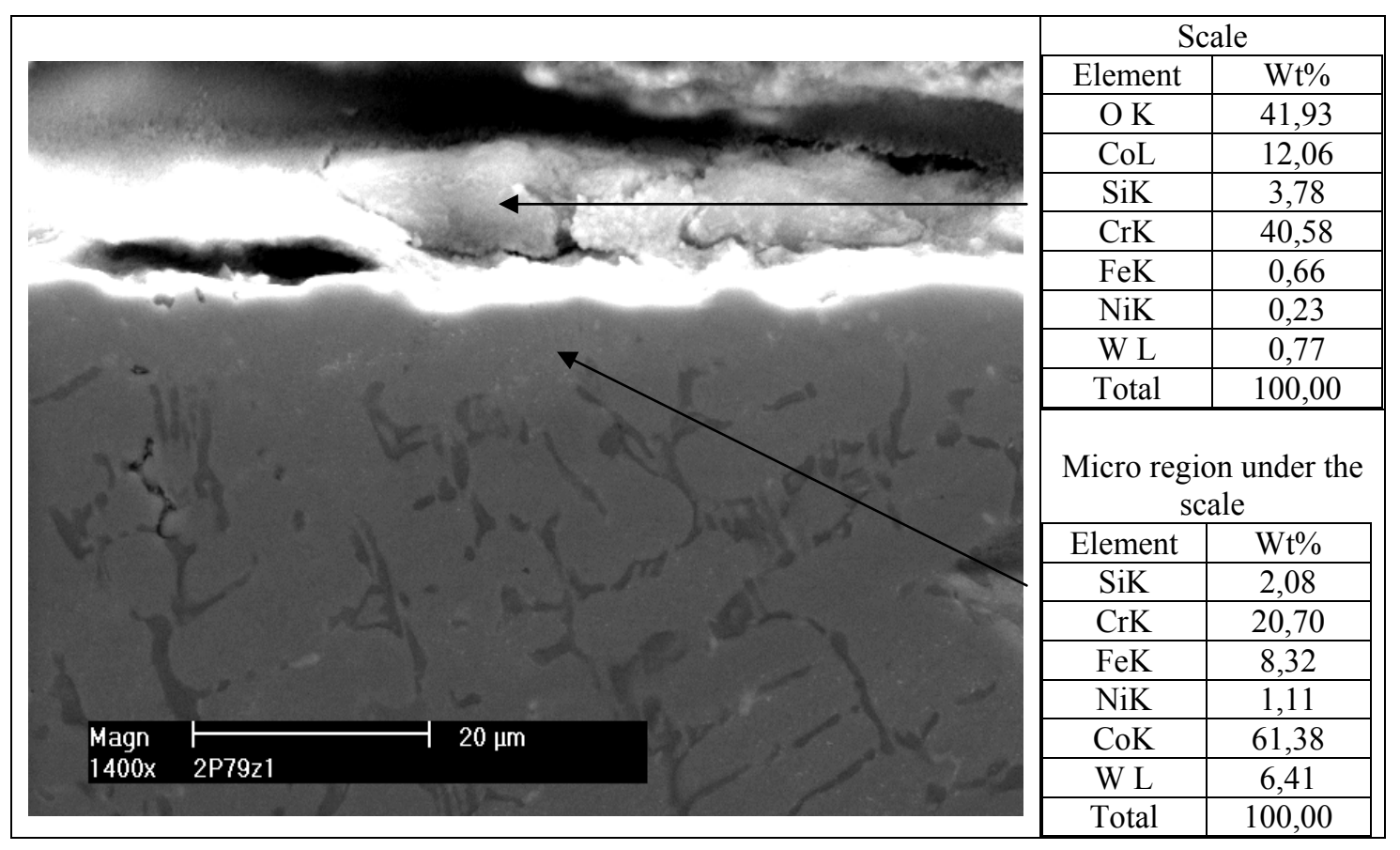

Fig. 3. Cross-section of the clad layer, close to the surface, oxidation at 750 and $900^{\circ} \mathrm{C}$ for 400 hours and chemical composition of the scale (EDS point analysis) and microregion under the scale

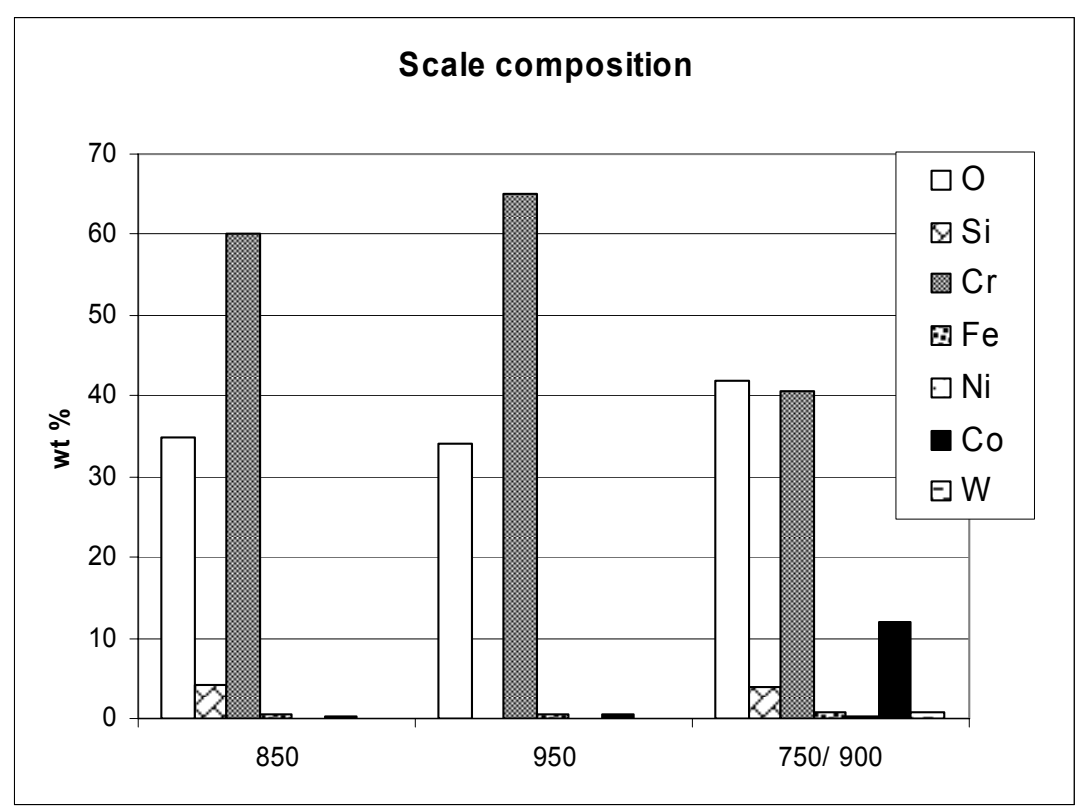

Fig. 4. Chemical composition of the scale (EDS point analysis) for different oxidation temperatures and times 


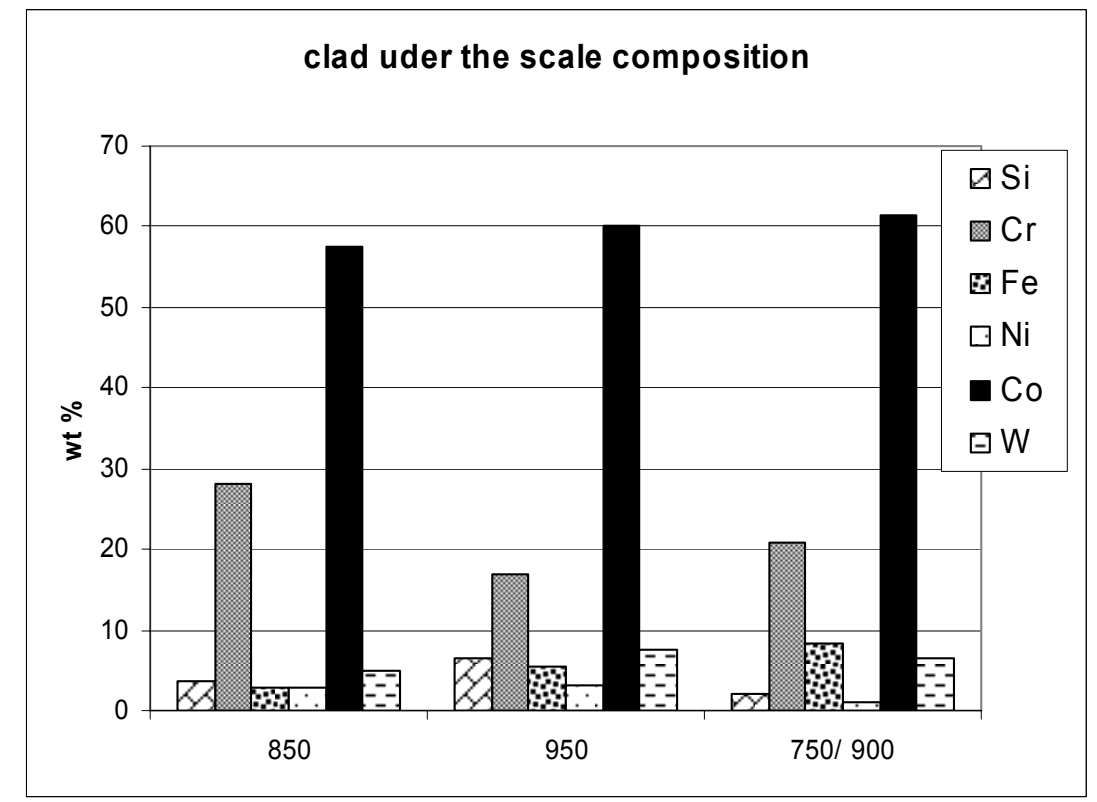

Fig. 5. Chemical composition of the microregion under the microregions under the scale for different oxidation temperatures and times

\section{CONCLUSIONS}

The oxidation reaction in investigated alloy was initiated by the formation of the outer scale of chromia which was nucleated and grow laterally. This scale subsequently grows in thickness by diffusion and caused depletion the underlying alloy of chromium. The high chromium content carbides situated on the dendrite boundaries were the main source - degradation and voids on the dendrite boundaries were showed on the Fig.1, 2 and 3. The increase of the oxidation temperature strongly influence on the thickness of the material which underwent the degradation process (Fig. 1 and 2). The time of the oxidation process influence on the chemical composition of the scale - shorter time exhibited "clear" chromia scale, while the longer time of exposition in oxidizing atmosphere led to formation more complex scale.

\section{REFERENCES}

1. B. Gleeson and M. A. Harpe; The Long-Term, Cyclic-Oxidation Behavior of Selected Chromia-Forming Alloys; Oxidation of Metals, Vol. 49, Nos. 3/4, 1998.

2. S. Uran, B. Veal, M. Grimsditch, J. Pearson, and A. Berger; Effect of Surface Roughness on Oxidation: Changes in Scale Thickness, Composition, and Residual Stress; Oxidation of Metals, Vol. 54, Nos. 1/2, 2000.

3. David J. Young, Brian Gleeson; Alloy phase transformations driven by high temperature corrosion processes; Corrosion Science 44(2002) 345-357. 
4. Liu, P.S., Liang, K.M., High-temperature oxidation behavior of the Co-base superalloy DZ40M in air; Oxidation of Metals Volume 53, Issue 3, 2000, Pages 351360.

5. B. Gleeson* and M. A. Harpe; The Long-Term, Cyclic-Oxidation Behavior of Selected Chromia-Forming Alloys; Oxidation of Metals, Vol. 49, Nos. 3/4, 1998.

6. Yuan, F., Sun, X., Guan, H., Hu, Z.; Cyclic oxidation behavior of a cobalt - base superalloy; Journal of the Chinese Society of Corrosion and Protection; Volume 22, Issue 2, 2002, Pages 115-117.

7. F M Yang; X F Sun; H R Guan; Z Q Hu; High-temperature low-cycle fatigue behavior of K4 S cobalt-base superalloy; Metallurgical and Materials Transactions; Apr 2003; 34A, 4; pg. 979.

8. P. Berthod, S. Michon, L. Aranda, S. Mathieu, J.C. Gachon; Experimental and thermodynamic study of the microstructure evolution in cobalt-base superalloys at high temperature; Computer Coupling of Phase Diagrams and Thermochemistry 27 (2003) 353-359.

9. D. L. Douglass and J. S. Armijo; The Influence of Manganese and Silicon on the Oxidation Behavior of Co-20Cr; Oxidation of Metals, Vol. 3, No. 2, 1971.

10. D. E. Jones and J. Stringer; The Effect of Small Amounts of Silicon on the Oxidation of High-Purity Co-25 wt. \% Cr at Elevated Temperatures Oxidation of Metals, Vol. 9, No. 5, 1975.

11. P. Y. Hou* and J. Stringert; Effect of Internal Oxidation Pretreatments and Si Contamination on Oxide-Scale Growth and Spalling Oxidation of Metals, Vol 33, Nos. 5/6, 1990.

12. B. Li and B. Gleeson; Effects of Silicon on the Oxidation Behavior of Ni-Base Chromia-Forming Alloys; Oxidation of Metals Volume: 65, Issue: 1-2, February 2006, pp. $101-122$. 